\title{
GAMBARAN STIGMA MASYARAKAT TERHADAP PASIEN GANGGUAN JIWA DI DESA BUKU
}

\author{
Fredy Akbar K $\mathbf{1}^{\mathbf{1}}$, Darmiati ${ }^{2}$, Ismawati ${ }^{\mathbf{3}}$ \\ ${ }^{1,2,3}$ Akademi Keperawatan YPPP Wonomulyo \\ *)fredykabira@gmail.com
}

\begin{abstract}
Abstrak
Gangguan jiwa adalah sindrom pola perilaku individu yang berkaitan dengan suatu gejala penderitaan dan pelemahan didalam satu atau lebih fungsi penting dari manusia, yaitu fungsi psikologik, perilaku, biologik, gaangguan tersebut mempengaruhi hubungan antara dirinya sendiri dan juga masyarakat Stigma yang terus tumbuh dimasyarakat dapat merugikan dan memperburuk bagi yang terkena label sosial ini.Penelitian ini bertujuan untuk melihat gambaran stigma masyarakat terhadap pasien gangguan jiwa.Penelitian ini menggunakan kuisioner, untuk mengetahui hasil dari stigma masyarakat terhadap pasien gangguan jiwa. Dalam penelitian ini sampel yang akan diambil yaitu berjenis kelamin perempuan yang berusia 25-40 tahun ke atas dengan jumlah sampel sebanyak 30 sampel. Metode yang digunakan dalam penelitian ini yaitu metode Deskriptif, metode deskriptif disini adalah salah satu jenis metode penelitian yang menyajikan gambaran lengkap untuk mendeskripsikan, menjelaskan yang menjadi objek penelitian.
\end{abstract}

Kata kunci: Gambaran, Stigma, Gangguan Jiwa

\begin{abstract}
Mental disorders are a syndrome of individual behavior patterns related to a symptom of suffering and weakness in one or more important human functions, namely psychological, behavioral, biological functions, these disorders affect the relationship between oneself and society.Stigma that continues to grow in society can harm and exacerbating those who are exposed to this social label. This study aims to see a picture of the stigma of society towards patients with mental disorders. This study used a questionnaire, to determine the results of the community's stigma against mental patients. In this study, the samples to be taken were women aged 25-40 years and over with a total sample size of 30 samples. The method used in this research is descriptive method, descriptive method here is one type of research method that presents a complete picture to describe, explain the object of research.
\end{abstract}

Keywords: Description, Stigma, Mental Disorders 


\section{Pendahuluan}

Gangguan jiwa menurut UndangUndang Nomor 18 Tahun 2014 Tentang Kesehatan Jiwa dapat diartikan sebagai orang dengan gangguan jiwa yang selanjutnya disingkat ODGJ adalah orang yang mengalami gangguan dalam pikiran, perilaku, dan perasaan yang termanifestasi dalam bentuk sekumpulan gejala dan/atau perubahan perilaku yang bermakna, serta dapat menimbulkan penderitaan dan hambatan bagi orang tersebut sehingga tidak dapat produktif secara sosial dan ekonomi. Gangguan jiwa dapat dibagi menjadi gangguan jiwa ringan dan gangguan jiwa berat (Islamiati, Widianti and Suhendar, 2018).

Stigma merupakan tanda atau tanda yang dibuat pada tubuh seseorang untuk diperlihatkan dan menginformasikan kepada masyarakat bahwa orang-orang yang mempunyai tanda tersebut merupakan seorang budak, kriminal, atau seorang penghianat serta suatu ungkapan atas ketidakwajaran dan keburukan status moral yang dimiliki oleh seseorang. Jadi stigma ini mengacu kepada atribut yang memperburuk citra seseoran (Purnama, Yani and Sutini, 2016). Stigma yang terus tumbuh dimasyarakat dapat merugikan dan memperburuk bagi yang terkena label sosial ini. mengatakan individu yang terkena stigma di masyarakat sulit untuk berinteraksi sosial bahkan dalam kasus terburuk dapat menyebabkan individu melakukan tindakan bunuh diri.

Selain itu penolakan untuk mencari pengobatan, penurunan kualitas hidup, kesempatan kerja yang lebih sedikit, penurunan peluang untuk mendapatkan pemukiman, penurunan kualitas dalam perawatan kesehatan, dan penurunan harga diri Sel itu penelitian yang dilakukan oleh) stigma tidak hanya berdampak pada klien gangguan jiwa, pada masyarakat yang ada sekitar pun ikut terkena, mereka merasa ketakutan kalau ada klien gangguan jiwa di lingkungan masyarakatnya karena mereka berpikir klien gangguan jiwa suka mengamuk dan mencelakai orang lain. Semua itu merupakan konsekuensi dari stigma gangguan jiwa (Purnama, Yani and Sutini, 2016).

Gangguan jiwa adalah masalah Kesehatan yang sangat umum terjadi di berbagai negara dan diperkirakan sekitar $12 \%$ dari beban penyakit secara global . Prevalensi gangguan jiwa adalah 1,7 per 1.000 dan dengan gangguan jiwa ringan sekitar 6\% dari total populasi Indonesia. Pemasalahan ini menjadi kompleks karena orang dengan gangguan jiwa (ODGJ) tidak hanya mendapatkan permasalahan akibat gejala dan penyakitnya, tetapi juga karena adanya stigma dan proses stigmatisasi terhadap mereka(Subu et al., 2018).

Menurut WHO masalah gangguan jiwa di seluruh dunia sudah menjadi masalah yang sangat serius. WHO memperkirakan sekitar 450 juta orang di dunia mengalami gangguan kesehatan jiwa. Prevalensi gangguan jiwa menurut WHO tahun 2015 menunjukkan bahwa secara global diperkirakan 350 juta orang mengalami depresi, 60 juta orang menderita gangguan afektif bipolar, 21 juta orang menderita gangguan skizofrenia dan 47,5 juta orang di dunia mengalami demensia (Putriyani, Sari and Hasmila, 2014). Bedasarkan data dari WHO (2016), terdapat sekitar 35 juta orang terkena depresi, 60 juta orang terkena bipolar 21 juta orang terkena skizofrenia, serta 47,5 juta orang terkena dimensia. Di Indonesia, dengan berbagai faktor biologis, psikologis, dan social dengan keanekaragaman penduduk, maka jumlah kasus gangguan jiwa terus bertambah yang berdampak pada penambahan beban Negara dan penurunan produktivitas manusia untuk jangka panjang (Zainuddin et al., 2019).

Riset Kesehatan Dasar (Riskesdas) tahun 2007 menyebutkan $14,1 \%$ penduduk Indonesia mengalami gangguan jiwa dari ringan hingga berat. Data dari 33 rumah sakit jiwa di seluruh Indonesia menyebutkan hingga kini jumlah penderita jiwa berat mencapai 2,5 juta orang. Di Indonesia prevalensinya sekitar $11 \%$ dari total penduduk dewasa (Sya'diyah, Afandi and Yoga, 2014). Berdasarkan data dari 
Tabe 1. Hasil dari Responden Gambaran Stigma Masyarakat terhadap pasien Gangguan jiwa

\begin{tabular}{|c|c|c|c|c|c|}
\hline No & Daftar Pernyataan & $\begin{array}{c}\text { Tidak } \\
\text { Setuju }\end{array}$ & $\%$ & Setuju & $\%$ \\
\hline 1. & $\begin{array}{l}\text { Menurut ibu Gangguan jiwa adalah perilaku yang dilakukan oleh } \\
\text { seseorang seperti ngomong sendiri, bicara kacau, emosinya mudah } \\
\text { berubah, tiba-tiba menangis kemudian tertawa, menarik diri dari } \\
\text { lingkungan sosial. }\end{array}$ & 5 & 16,6 & 25 & 83,3 \\
\hline 2 & $\begin{array}{l}\text { Menurut ibu Gangguan jiwa itu dapat terjadi karena seseorang yang } \\
\text { tidak dapat menyelesaikan masalah yang dialami. }\end{array}$ & 17 & 56,6 & 13 & 43,3 \\
\hline 3 & $\begin{array}{l}\text { Menurut ibu Jika ada anggota keluarga yang mengalami gangguan } \\
\text { kesehatan jiwa, maka hal itu dapat memalukan dan dapat merusak } \\
\text { nama baik keluarga }\end{array}$ & 11 & 36,6 & 19 & 63,3 \\
\hline 4 & Menurut ibu penderita gangguan jiwa perlu mendapat pengobatan & 2 & 6,6 & 28 & 93,3 \\
\hline 5 & $\begin{array}{l}\text { Menurut ibu penderita gangguan jiwa itu lebih baik dikurung saja } \\
\text { karena akan mengganggu orang lain }\end{array}$ & 7 & 23,3 & 23 & 76,6 \\
\hline
\end{tabular}

Riskesdas jumlah seluruh Rumah Tangga (RT) yang dianalisis adalah 294.959 terdiri dari 1.027.763 Anggota Rumah Tangga (ART) yang berasal dari semua umur. Rumah tangga yang menjawab memiliki ART dengan gangguan jiwa berat sebanyak 1.655, terdiri dari $1.588 \mathrm{RT}$ dengan 1 orang ART, 62 RT memiliki 2 orang ART, 4 RT memiliki 3 ART, dan 1 RT dengan 4 orang ART yang mengalami gangguan jiwa berat. Jumlah seluruh responden dengan gangguan jiwa berat adalah sebanyak 1.728 orang (Putriyani, Sari and Hasmila, 2014).

$$
\text { Hasil Riset Kesehatan Dasar }
$$

(Riskesdas) tahun 2013, menunjukan bahwa prevalensi orang dengan gangguan jiwa adalah 1,7 per 1000 penduduk atau sekitar 400.000 orang (Sarifuddin, 2016). Sulawesi Barat adalah provinsi ke-33 di Indonesia yang merupakan pemekaran dari provinsi induk Sulawesi Selatan. Provinsi Sulawesi Barat belum mempunyai rumah sakit jiwa sehingga penanganan pasien gangguan jiwa belum optimal. Berdasarkan studi pendahuluan di Kabupaten Majene, terdapat 217 orang mengalami gangguan jiwa (Purnomo et al., 2016).

\section{Metode Penelitian}

Pada penelitian ini menggunakan metode survei dengan pendekatan Deskriptif. Dalam penelitian ini sampel yang akan diambil yaitu berjenis kelamin perempuan yang berusia 25-40 tahun ke atas dengan sampel sebanyak 30 sampel. Penelitian dilakukan mulai bulan: agustus Lokasi : didesa buku.

\section{Hasil}

Berdasarkan 30 responden dalam penelitian di dapatkan ibu yang berumur 2527 tahun sebanyak 4 orang $(13,3 \%)$, yang berumur $30-35$ tahun 8 orang $(26,6 \%)$, umur $36-40$ tahun sebanyak 12orang (40\%), dan yang umur 41-45 tahun sebanyak 10 orang (20\%). Hasil demografi pendidikan didapatkan SD sebanyak 19 orang $(63,3 \%)$, yang berpendidikan SMP sebanyak 3 orang (10\%), pendidikan SMA sebanyak 6 orang (20\%), dan yang berpendidikan perguruan tinggi sebanyak 2 orang $(6,6 \%)$. Hasil demografi pekerjaan didapatkan ibu yang bekerja sebagai IRT sebanyak 18 orang (60\%), yang bekerja sebagai Wiraswasta sebanyak 6 orang (20\%), petani 1 orang $(3,3 \%)$, Honorer sebanyak 4 orang $(13,3 \%)$ dan yang bekerja sebagai pedagang 1 orang $(3,3 \%)$. 


\section{Pembahasan}

Berdasarkan dari 5 tabel diatas bahwa tabel 1,2,dan 4 mendapatkan hasil Stigma masyarakat yang sesuai dengan pemahaman tentang Gangguan Jiwa, hal ini didapatkan dari data umum yaitu usia, Pendidikan, Pekerjaan sebagai Informasi. Dan sebagian Responden Berumur 36-40 tahun dengan hasil sebanyak 12 orang (40\%), adapun penjelasannya adalah dengan bertambahnya usia maka pola fikir juga akan berubah, usia yang sudah matang membuat pola pikir akan menjadi lebih baik, terbukti dengan pola fikir 36 tahun keatas memiliki pandangan yang positif terhadap orang gangguan jiwa. Dan faktor pekerjaan juga bisa membuat stigma menjadi positif dikarenakan mempermudah berinteraksia antara satu dengan yang lainnya.

Adapun hasil dari tabel 3 dan 5 mendapatkan hasil Stigma Masyarakat yang tidak sesuai dengan pemahaman tentang Gangguan Jiwa, hal ini bisa terjadi dikarenakan rendahnya tingkat pendidikan membuat penerimaan dan pemahaman menjadi terbatas di tambah lagi pandangan buruk tentang orang gangguan jiwa yang sudah tertanam membuat pandangan terhadap orang gangguan jiwa menjadi negative dimana dari hasil diatas di dapatkan ada 19 orang $(63,3 \%)$ yang tingkat pendidikannya adalah SD atau sekolah dasar.

\section{Simpulan dan Saran}

Berdasarkan hasil penelitian dan pembahasan dapat di ambil kesimpulan bahwa sebagian besar Responden Masyarakat Desa Buku Kecamatan Mapilli Kabupaten Polewali Mandar Provinsi Sulawesi Barat ada memiliki stigma negatif atau yang mempunyai stigma yang tidak sesuai dan dari hasil penelitian ini dapat disimpulkan bahwa kiranya untuk masyarakat agar bisa menghargai penderita gangguan jiwa. Dan untuk instansi kesehatan agar bisa memberikan pemahaman tentang gangguan jiwa kepada masyarakat.

\section{Daftar Pustaka}

Islamiati, R., Widianti, E. and Suhendar, I.
(2018) 'Sikap Masyarakat Terhadap Orang dengan Gangguan Jiwa di Desa Kersamanah Kabupaten Garut', Sikap Masyarakat Terhadap Orang dengan Gangguan Jiwa di Desa Kersamanah Kabupaten Garut, VI(2), pp. 195-205.

Purnama, G., Yani, D. I. and Sutini, T. (2016) 'Gambaran Stigma Masyarakat Terhadap Klien Gangguan Jiwa Di RW 09 Desa Cileles Sumedang', Gambaran Stigma Masyarakat Terhadap Klien Gangguan Jiwa Di RW 09 Desa Cileles Sumedang, 2(1), pp. 29-37.

Purnomo, E. et al. (2016) 'Klien Gangguan Jiwa Di Rumah', 2.

Putriyani, Sari, D. and Hasmila (2014) 'Stigma of the Society Towards People With Mental Disorders in Kuta Malaka Sub-District Great Aceh Regency'.

Sarifuddin, S. (2016) 'GAMBARAN PUBLIC STIGMA TERHADAP

ORANG DENGAN GANGGUAN JIWA', GAMBARAN PUBLIC STIGMA TERHADAP ORANG DENGAN GANGGUAN JIWA DI DESA ROGODONO KECAMATAN BUAYAN KABUPATEN KEBUMEN, 6, p. 1939.

Subu, M. A. et al. (2018) 'Stigma, Stigmatisasi , Perilaku Kekerasan dan Ketakutan diantara Orang d engan Gangguan Jiwa ( ODGJ ) di Indonesia: Penelitian Constructivist Grounded theory Stigma , Stigmatization , Violence and Fear among People with Mental Illness ( PWMI ) in Indone', 30(1), pp. 53-60.

Sya'diyah, S. N., Afandi, A. A. and Yoga (2014) 'Stigma Masyarakat Terhadap Orang Sakit Jiwa (Suatu Studi Di Desa Trucuk Kecamatantrucuk Kabupaten Bojonegoro Tahun 2014no Title J', Stigma Masyarakat Terhadap Orang Sakit Jiwa (Suatu Studi Di Desa Trucuk Kecamatantrucuk Kabupaten Bojonegoro Tahun 2014, 8(33), p. 44.

Zainuddin, Z. et al. (2019) 'Stigma Masyarakat Terhadap Penderita Gangguan Jiwa (Study Kualitatif di Wilayah Kerja Puskesmas Kewapante 
Kecamatan Kewapante Kabupaten Sikka Provinsi NTT )', (October). 